\title{
EL ACEITE EN LA ANTIGÜEDAD: LUMINOSO TRIUNFO DE LA PAZ Amalia Lejavitzer*
}

\section{Un antiguo pensamiento latino} advierte ne et operam et oleum perdas, 'no desperdicies ni el aceite ni el trabajo', es decir, no pierdas tiempo, no emplees ni el aceite que da luz a tus lámparas ni el esfuerzo de tu trabajo en algo que no lo amerita. Este conocido proverbio - citado por Cicerón y por Plauto-, ${ }^{1}$ en general, contrapone el buen uso del aceite, como fuente permanente de luz, al desperdicio o abuso que, a juicio de muchos, implica utilizar este líquido vital en quehaceres frívolos.

Si pensamos que, durante siglos (el descubrimiento de la lámpara de gas data del siglo XIX), viviendas, palacios y templos fueron alumbrados gracias a lámparas ${ }^{2}$ alimentadas con aceite de olivo, ${ }^{3}$ resulta inconveniente malgastar inútilmente una materia prima tan valiosa para la existencia humana. Marcial, por ejemplo, considera que gastar el aceite doméstico en la palestra es un despilfarro, cuando elogia el hecho de que, en la villa de su amigo Julio Faustino, 'no desperdicia

* Centro de Estudios Clásicos, Instituto de Investigaciones Filológicas, UNAM.

${ }^{1}$ Cic., Att., 2, 17, 1: ne et opera et oleum philologiae nostrae perierit; también en Fam., 7, 1, 3: ipse Pompeius confitetur se et operam et oleum perdidisse. Plaut. Poen., 332: tum pol ego et oleum et operam perdidi.

${ }^{2}$ Cfr. Mart., XIV, 43, 2: uncta lucerna (aceitosa lámpara).

${ }^{3}$ Cfr. Ex, 27, 20: "Mandarás a los israelitas que te traigan aceite puro de oliva molida para el alumbrado, para alimentar continuamente la llama." 
aceite, untado, el atleta' ${ }^{4}$ En ese verso, el epigramatista usa el término latino palaestrita, es decir, el maestro o el director de una escuela de luchadores o de una palestra, pero detrás de esta voz de origen griego, sin duda, hay que ver una condena a los hábitos extranjeros, al lujo amanerado y a la riqueza suntuosa, frecuentes en los tiempos del Imperio, los cuales atentaban contra la austeridad y mesura de las virtudes de los parcos romanos de antaño. Por ello, el buen uso del aceite en la vida cotidiana deviene signo de sobriedad, moderación y propiedad. Ya Cicerón, al referirse a ciertos discursos que, siendo adecuados para la ejercitación en las escuelas de retórica, resultan inapropiados para el foro, dice que ese género de oraciones, por ser nítido y alegre, parece 'más propio de la palestra y del aceite', ${ }^{5}$ es decir, no pertinente para los discursos forenses. En este sentido, Juvenal ataca la verborrea inútil de algunos autores, a quienes censura que en su obra "se gasta demasiado tiempo y también demasiado aceite, pues sin ninguna moderación la milésima página surge para todos $\mathrm{y}$, causando muchos daños, crece el escrito". ${ }^{6}$

Ahora bien, en la antigüedad, el aceite se empleó no sólo en la iluminación o en el gimnasio. De hecho, tuvo incontables aplicaciones en la vida diaria: en la cocina, como alimento y condimento por excelencia; en la cosmética, para la elaboración de ungüentos y perfumes; en la metalurgia, para templar metales ${ }^{7}$ en la medicina, para la fabricación de diversas clases de remedios. Y ni qué decir de sus usos en el ámbito religioso, donde alcanzó, sin duda, el máximo grado de valoración; baste mencionar, a modo de ejemplo, 'los santos óleos' de la religión católica o el nombre mismo de 'Cristo' [vid., p. 49: n.r.).

Aquí resulta necesario acotar que, para los antiguos pueblos del Mediterráneo, el aceite por antonomasia es el que se obtiene del fruto

${ }^{4}$ Mart., III, 48, 25: nec perdit oleum lubricus palaestrita.

${ }^{5}$ Cic., de Or., I, xviii, 81: nitidum quoddam genus est verborum et laetum, et palaestrae magis et olei, quam huius civilis turbae ac fori.

${ }^{6}$ Juv., VII, 99-101: Perit hic plus temporis atque olei plus. / Nullo quippe modo millensima pagina surgit / omnibus et crescit multa damnosa papyro.

${ }^{7}$ Isid., Orig., XVI, 21, 4: In acuendo ferro oleo delectatior fit acies; unde et tenuiora ferramenta oleo restingui mos est, ne aqua in fragilitatem durentur. 
del olivo. De hecho, de ahí toma su nombre; al respecto dice Isidoro que "el olivo es llamado por los griegos $\varepsilon$ " $\lambda \alpha$ เov, de donde se deriva que en latín se diga oliva. Por otra parte, el mismo árbol es llamado olea; el fruto, oliva; su jugo, oleum". ${ }^{8}$ Sin embargo, esta distinción no siempre parece tan obvia, sobre todo en latín, pues los términos oliva y olea designan tanto al árbol como a su fruto, la aceituna, y las voces olivum y oleum, al aceite. Más aún, estos dos últimos vocablos frecuentemente fueron usados como sinónimos de unguentum, en especial por los poetas, quienes, probablemente por razones métricas, con frecuencia pasan por alto las diferencias semánticas que el sabio hispalense se preocupa en precisar: "el aceite es puro y no está mezclado con ninguna otra cosa. En cambio, el ungüento es todo aquello que, confeccionado a partir del aceite común, es enriquecido por la mezcla de diversas especias". ${ }^{9}$ Así, mientras Catulo escribe 'fragante de aceite sirio y guirnaldas' ${ }^{10}$ y Propercio dice 'tu tersa cerviz manará el aromático aceite', ${ }^{11}$ Marcial titula la penúltima de sus composiciones del libro XIII, Vnguentum, voz que usualmente se ha traducido al castellano por Perfume o Ungüento, aunque tal vez sería más correcto verterla como Aceite, ya que, por varios motivos, ${ }^{12}$ puede pensarse que

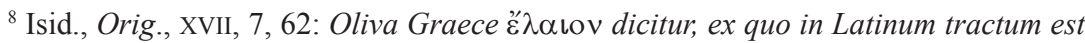
ut oliva dicatur. Olea autem ipsa arbor est; fructus oliva; sucus oleum.

${ }^{9}$ Isid., Orig., IV, 12, 6: Oleum est purum nullique rei admixtum. Vnguentum vero est omne quod ex communi oleo confectum aliarum specierum commixtione augetur.

${ }^{10}$ Cat., VI, 8: Sertis ac Syrio fragans oliuo. Trad. Rubén Bonifaz Nuño, en Cayo Valerio Catulo, Cármenes, intr., vers. rítm. y nts., 1969, México, UNAM, Bibliotheca Scriptorum Graecorum et Romanorum Mexicana.

${ }^{11}$ Prop., III, 17, 31: leuis odorato ceruix manabit oliuo. Trad. Rubén Bonifaz Nuño, en Sexto Propercio, Elegías, intr., vers. rítm. y nts., 1974, México, UNAM, Bibliotheca Scriptorum Graecorum et Romanorum Mexicana.

${ }^{12}$ Por una parte, cabe recordar que el libro trece del epigramatista, titulado Xenia, aludiendo a los presentes que eran ofrecidos como dones de hospitalidad, reúne composiciones todas ellas referidas a productos alimenticios, a excepción de los tres epigramas iniciales y del último. Los primeros, a modo de introducción, explican el significado y el contenido de la colección, mientras que el dístico final concluye el libro de la misma manera en que terminaría un banquete, con 'Coronas de rosas,' (Mart., XIII, 127) y sugiere la tradicional 'costumbre de regalar coronas de flores al término de los convivios' (cfr. A. Lejavitzer, Hacia una génesis del epigrama en Marcial: Xenia y Apophoreta, 2000, México, UNAM (Mirador de posgrado), 
el vocablo latino está empleado como un término genérico, para referirse no sólo a los óleos aromáticos, sino también, en sentido amplio, al aceite de uso doméstico, ${ }^{13}$ cuando el epigramatista aconseja que 'ni el aceite ni los vinos dejes nunca a tu heredero'. ${ }^{14}$

No obstante, en la cocina romana siempre prevaleció el término oleum, lo cual pone de manifiesto no sólo el hecho del predominio absoluto del olivo en la fabricación de aceites comestibles, sino también el escaso uso de las grasas de origen animal en la culinaria, pues, aun cuando éstas fueron conocidas por los latinos, ${ }^{15}$ nunca fueron ni empleadas con la misma frecuencia ni apreciadas de igual manera que el aceite. La utilización de grasas de cerdo, vaca, cabra y otros animales se reservó sobre todo para la medicina, según podemos deducir leyendo a Plinio, por ejemplo, cuando dice: "el coágulo de ciervo, el tan elogiado de cabrito, pero en primer lugar el de conejo, el cual también cura la diarrea", ${ }^{16}$ o cuando entre las propiedades medicinales de la manteca de vaca menciona que es 'astringente, emoliente, reconstituyente y purgante'. ${ }^{17}$ Más aún, el uso de manteca de vaca (de ahí, bubulus, de donde deriva, según Plinio, la palabra latina que le da nombre, butyrum $)^{18}$ se considera una característica distintiva de las costumbres alimenticias de los pueblos bárbaros, quienes consideraban esta grasa de origen animal 'un alimento suntuosísimo':19

p. 23; también nota 73). Así, atendiendo a la estructura del libro, la cual responde al curso de un banquete, sería más adecuado traducir unguentum por aceite. Por otra parte, el epigrama en cuestión está precedido por composiciones alusivas al aceite, al garo, al vinagre y al vino, y en este libro, el epigramatista por lo general agrupa sus poemas en conjuntos temáticos: otra razón por la que es factible pensar en un uso genérico del término latino.

${ }^{13}$ Cfr. también, en el libro XIII, el epigrama 101, titulado Oleum Venafrum, donde emplea el término unguentum, como sinónimo de aceite: unguentum quotiens sumis, et istud olet.

${ }^{14}$ Mart., XIII, 126, 1: Vnguentum heredi numquam nec uina relinquas.

${ }^{15}$ Cfr. P1., N. H., 11, 239; 18, 105; 28, 133.134.

${ }^{16} \mathrm{Pl} .$, N. H., 11, 239: coagulum hinnulei, leporis, haedi laudatum, praecipuum tamen dasypodis, quod et profluvio alvi medetur.

${ }^{17} \mathrm{Cfr}$. Pl., N. H., 28, 134: natura eius (sc. butyri) adstringere, mollire, replere, purgare.

${ }^{18}$ Cfr. Pl., N. H., 28, 133.

${ }^{19}$ Pl., N. H., 28, 133: E lacte fit et butyrum, barbararum gentium lautissimus cibus et qui divites a plebe discernat. 
Es admirable - dice Plinio- que los pueblos bárbaros, que viven gracias a la leche, hayan ignorado y despreciado durante tantos siglos la virtud del queso; por el contrario, ellos condensan la leche en una agradable, acre y grasosa manteca. Ésta es espuma de leche, más compacta y espesa que lo que se llama suero; sin ignorar que en ella está el vigor del aceite, y que de esa manera es usada para untar, por todos los bárbaros y por nuestros niños. ${ }^{20}$

Si bien, en la cita anterior, Plinio menciona que la manteca fue usada específicamente para la alimentación de los niños, su uso entre los romanos fue muy restringido. Sin duda, la preferencia por el aceite de olivo ante la grasa animal responde a factores culturales que condicionan esa elección, pues el aceite deviene símbolo y emblema de las culturas mediterráneas, como veremos más adelante. En efecto, los límites geográficos del área mediterránea corresponden a los que trazan las plantaciones de olivares, pues, aunque Virgilio diga que

los olivos no exigen ningún cultivo, ni esperan nada de la corva podadera ni de los tenaces rastrillos, cuando ya han prendido en los campos y han recibido los aires; la misma tierra satisfecha, una vez abierta con el curvo diente, proporciona el jugo y, con la reja del arado, henchidos frutos, ${ }^{21}$

lo cierto es que su crecimiento requiere de ciertas condiciones geográficas y climáticas que sólo ofrece la cuenca del Mediterráneo. Ya los autores antiguos, como Teofrasto, fueron conscientes de ello; afirmaban que el olivo sólo nace en tierras que no estén a más de sesenta

${ }^{20} \mathrm{Pl} .$, N. H., 11, 239: Mirum barbaras gentes quae lacte vivant ignorare aut spernere tot saeculis casei dotem, densantes id alioqui in acorem iucundum et pingüe butyrum. Spuma id est lactis concretior lentiorque quam auod serum vocatur; non omittendum in eo olei vim esse et barbaros omnes infantesque nostros ita ungui.

${ }^{21}$ Virg., G., II, 420-422: Contra non ulla est oleis cultura, neque illae / procuruam exspectant falcem rastrosque tenacis, / cum semel haeserunt aruis aurasque tulerunt; / ipsa satis tellus, cum dente recluditur unco, / sufficit umorem et grauidas, cum uomere, fruges. 
kilómetros del mar, ${ }^{22}$ y que, además, exige un clima templado durante todo el año para poder florecer: "sin duda -dice el autor de la Historia natural- el suelo y el clima tienen suma importancia para ellos (sc. los olivos)", 23 al respecto, Plinio el Joven escribe en una de sus cartas que al pie de los Apeninos "el clima en invierno es frío y gélido; esto impide por completo que haya mirtos, olivos y algunos otros ( $s c$. árboles) que sólo se aclimatan en una continua tibieza". ${ }^{24}$

En este sentido, el recetario titulado De re coquinaria, atribuido a Apicio, es clara muestra del extenso empleo del olivo (frutos y jugo) en la gastronomía romana, frente al escaso uso de grasas de origen animal; allí, apenas se menciona una sola vez el término adipes fasiani, esto es, 'grasas de faisán', para preparar unas albóndigas, que sin lugar a dudas representaban un platillo sofisticado y poco ordinario en la mesa cotidiana de los romanos comunes y corrientes:

AlBóNDIGAS RELLENAS: tomas grasa fresca de faisán, dejas que se endurezca y haces con ella pequeños dados; con pimienta, garo, careno aderezas la albóndiga, cocinas con hidrogaro $^{25}$ y sirves. ${ }^{26}$

Aparte de este caso raro, de las grasas de origen animal, la de cerdo (adeps suillus o simplemente adeps) ${ }^{27}$ fue la única que eventualmente se empleaba en la culinaria, en especial, en la pastelería, como pone

${ }^{22}$ Apud Pl., N. H., 15, 1: Oleam Theophrastus [...] negavit nisi intra XXXX [milia] passum ab mari nasci.

${ }^{23} \mathrm{Pl} .$, N. H., 15, 4: sine dubio et in iis (sc. oleis) solum maxime caelumque refert.

${ }^{24} \mathrm{Pl}$., Ep., V, vi, 4: Caelum est hieme frigidum et gelidum; myrtos oleas quaeque alia assiduo tepore laetantur, aspernatur ac respuit.

${ }^{25}$ Hidrogaro: compuesto de garo y agua. El garo (garum) era un líquido apreciadísimo por los antiguos romanos, se fabricaba de entrañas de pescado maceradas en sal, y constituía el principal condimento y sazonador de la gastronomía latina. Cfr. Amalia Lejavitzer, "Garum paradoxum: misterio y maravilla de la cocina romana", Noua Tellus, 18-2, 2000, p. 115-28.

${ }^{26}$ Apic., II, ii, 1: 1. ESICIA PLENA: Accipies adipes fasiani recentes, praeduras et facis ex eo tessellas, cum pipere, liquamine, careno in isicio includes, ex idrogaro coques et inferes.

${ }^{27}$ Cfr. J. André, L'Alimentation et la cuisine à Rome, Paris, Les Belles Lettres, 1981, p. 184 . 
de manifiesto el nombre que los latinos daban a lo que hoy llamaríamos mantecadas: adipata. $^{28}$ Estos grasosos pastelitos constituían el desayuno o el refrigerio de los niños cuando iban a la escuela, lo cual ciertamente se puede relacionar con el comentario de Plinio respecto a la inclusión de la manteca en la alimentación infantil; Marcial nos ha dejado un hermoso testimonio de ello en el epigrama titulado precisamente 'Mantecadas' (Adipata):

Levantaos: a los niños ya vende desayunos el panadero y suenan por doquier las crestadas aves de la luz. ${ }^{29}$

Ahora bien, así como una sola receta apiciana incluye grasa en su confección, son más de doscientas cuarenta las que mencionan el aceite; éste aparece citado para condimentar las distintas hortalizas; ${ }^{30}$ como líquido de cocción, para hervir ${ }^{31}$ y para freír, ${ }^{32}$ o para untar, antes de asar, ${ }^{33}$ las diversas clases de carnes y pescados; en suma, para aderezar casi cualquier platillo, frecuentemente se aconseja oleo condies, 'se condimenta con aceite'.

Así pues, el libro tercero del recetario de Apicio, 'Las hortalizas', ofrece un sinnúmero de vegetales (calabacitas, coles, brócolis, acelgas, apios, nabos, puerros, lechugas) crudos o hervidos o en puré, aliñados con el jugo de la oliva. ${ }^{34}$

Además, el aceite, junto con la miel, es el ingrediente principal en la confección de una enorme variedad de salsas, para acompañar diversos platillos preparados con carne (de res o ternera, de jabalí,

${ }^{28}$ Cfr. Juv., VI, 631: liuida [...] adipata; Mart. XIV, 223.

${ }^{29}$ Cfr. Mart., XIV, 223: Surgite: iam uendit pueris ientacula pistor. / Cristataeque sonant undique lucis aves.

${ }^{30}$ Cfr. el libro tercero, 'Las hortalizas', donde prácticamente la totalidad de las recetas allí incluidas constituyen un contundente ejemplo de ello.

${ }^{31}$ Cfr. Apic., VI, ii, 3.

${ }^{32}$ Cfr., por ejemplo, Apic., VII, xviii, 1: ex oleo friges.

${ }^{33}$ Cfr., Apic., VII, xviii, 2: sale puro et oleo assabis; también viii, 1: et sic praedurantur in oleo et liquamine, inde assantur in clibano uel craticula.

${ }^{34}$ Cfr. Apic., III, iv, 6; ix, 1; x, 1; xi, 1; xiii, 2; xv, 3. 
de ciervo, de cabra, de cabrito o cordero, de cerdo, de liebre) ${ }^{35}$ con pescado (torpedo, salmonete, morena, atún, dorada, dentón); ${ }^{36}$ con productos del mar (como anguila, langosta, erizo, ostras, calamares), ${ }^{37}$ o con distintas aves (avestruz, grulla, pato, perdiz, francolín, tórtola, palomo, flamenco, oca, y pollo). ${ }^{38}$

Sin embargo, el papel del olivo en la cocina apiciana no termina aquí: los postres tampoco escaparon a su señorío; el aceite también fue componente fundamental para la preparación de los dulces romanos, lo cual no es de extrañar, pensemos, por ejemplo, en los buñuelos mexicanos o en las castizas torrejas. Afortunadamente, el De re coquinaria nos ha conservado un par de recetas de lo que podrían ser los antepasados latinos de aquellos dulces:

OTRA RECETA PARA DULCES: Tomas harina, la cocinas en agua caliente hasta que hagas una papilla muy compacta, después la extiendes en una fuente. Cuando se haya enfriado, la cortas como los dulces y fríes en aceite de la mejor calidad. Retiras, bañas con miel, espolvoreas pimienta y sirves. Es mejor, si en lugar de agua, pones leche. ${ }^{39}$

OTRA RECETA PARA DULCES: Quiebras la corteza de un pan del más puro trigo y formas trozos grandes. Los mojas en leche, los fríes en aceite, los bañas con miel y sirves. ${ }^{40}$

Probablemente en la primera receta, al decir oleo optimo, Apicio se refiera al aceite producido en la región del Venafro, en Campania,

${ }^{35}$ Cfr. Apic., VIII, i, 3-8, ii, 1-7, iii, 1-3; iv, 1; 3; v, 1-4; vi, 1-10; vii, 1; 7-9; 17; viii, 1-2; 4-7; 10-13.

${ }^{36}$ Apic., IX, ii, 1-2; X, i, 11-12; ii, 1-6; iii, 1-10.

${ }^{37}$ Apic., IX, I, 1; 5; iii, 1-2; vi; viii, 1; 3; X, iv, 1-2.

${ }^{38}$ Apic., VI, i, 1-2; ii, 1-5; iii, 1 y 3; iv, 1-3; vi, 2; viii, 1-2; ix, 3-4; 6-7; 11-15.

${ }^{39}$ Apic., VII, xiii, 6: ALITER DVLCIA: Accipes similam, coques in aqua calida ita ut durissimam pultem facias, deinde in patellam expandis. Cum refrixerit, concidis quasi dulcia et frigis in oleo optimo. Leuas, perfundis mel, piper aspargis et inferes. Melius feceris, si lac pro aqua miseris.

${ }^{40}$ Apic., VII, xiii, 3: ALITER DVLCIA: Siligineos rasos frangis et bucellas maiores facies. In lacte infundis, frigis in oleo, mel superfundis et inferes; también id., 9. 
el cual, sin duda, fue el más apreciado por los antiguos romanos, ${ }^{41}$ así, Varrón, elogiando la prodigalidad del suelo italiano, se pregunta "¿Qué escanda se compara a la de Campania? ¿Qué trigo, al de Apulia? ¿Qué vino, al de Falerno? ¿Qué aceite, al del Venafro?"

Plinio concuerda con Varrón, pues establece una jerarquía de cuáles son los aceites de mejor calidad en Italia y en todo el mundo: en el primer lugar sitúa al originario de los campos venafros, dado su olor y gusto delicados; en el segundo, determina un empate entre el aceite proveniente de la tierra de Istria y el de Bética, en el sur de Hispania; después de éstos, coloca a todos los demás. ${ }^{43}$ Marcial, por su parte, con su concisión acostumbrada, sólo necesita dos versos para elogiar la calidad del aceite hispano, el de Córdoba, ciudad en Bética:

Córdoba, más dichosa que el oleoso Venafro, y no menos perfecta que un ánfora de Istria. ${ }^{44}$

Así pues, después del óleo venafro, los romanos apreciaban a la par tanto el proveniente de la Península Ibérica como el de la región de Istria; Apicio nombra al primero, oleum spanum; al segundo, oleum liburnicum, es decir, aceite de Liburnia, pueblo en la región del Danubio, entre Istria y Dalmacia. De hecho, en De re coquinaria encontramos una curiosa receta para falsificar este último:

${ }^{41}$ Cfr., por ejemplo, Juv., 5, 86: ipse Venafrano piscem perfundit; Hor., Od., 2, 6, 15-6: uiridique certat / baca Venafro [...]; id., S., II, 4, 68-9: insuper addes / pressa Venafranae quod baca remisit olivae; id., 2, 8, 45-6: [...] oleo, quod prima Venafri / pressit cella; Mart., XIII, 101: OLEVM VENAFRVM. Hoc tibi Campani sudauit baca Venafri: / unguentum quotiens sumis, et istud olet.

${ }^{42}$ Varr., R. R., i, ii, 6: Quod far conferam Campano? Quod triticum Apulo? Quod uinum Falerno? Quod oleum Venafro?

${ }^{43}$ Cfr., Pl., N. H., XV, iii, 8.

${ }^{44}$ Mart., XII, 63, 1-2: Vncto Corduba laetior Venafro, / Histra nec minus absoluta testa. 


\section{ASÍ SE HACE EL ACEITE LIBÚRNICO}

En aceite hispano, echas helenio, juncia, hojas frescas de laurel -todo ello triturado y cernido, hasta que se haya reducido a un polvo muy fino- y sales tostadas y trituradas. Mézclalo con cuidado durante tres días o más. Después de esto, déjalo reposar durante cierto tiempo, y todos pensarán que es aceite libúrnico. ${ }^{45}$

Esta receta especifica el uso de aceite hispano, que Apicio asimismo menciona como ingrediente en la confección de diversos platillos. ${ }^{46}$

No obstante, el aceite, sin importar su procedencia, sea venafro, libúrnico o hispano, ha sido desde siempre impronta característica no sólo de la cocina, sino de la culturas griega y romana de ayer y hoy, y, en general, de todas las civilizaciones mediterráneas, dado que, según lo hemos expuesto, este líquido resultaba vital para la existencia cotidiana de los pueblos antiguos. Desde siempre, se le ha considerado un nutrimento gustoso y saludable, 'como un alimento precioso, rico en sabores y pleno de energía'; ${ }^{47}$ un ingrediente fundamental para la gastronomía latina, y un beneficio para la salud, pues, aun cuando en la antigüedad se ignoraban sus efectos positivos para controlar el colesterol, constituía la base para la elaboración de remedios y ungüentos destinados a la curación de ciertos padecimientos de la garganta $\mathrm{y}$, sobre todo, de heridas de la piel, como grietas, llagas, quemaduras. ${ }^{48}$

Más aún, desde los primeros tiempos de la humanidad, el aceite ha sido tenido por un don divino; para los griegos, fue la mismísima

${ }^{45}$ Apic., I, iv: Olevm Libvrnicvm sic facies: In oleo Spano mittes hellenium et cyperi et folia lauri non vetusta, tunsa omnia et cribellata, ad levissimum pulverem redacta, et sales frictos et tritos, et per triduum vel plus promisce diligenter. Post haec aliquanto tempore patere requiescere, et Liburnicum omnes putabunt.

${ }^{46}$ Apic., VI, ix, 15.

${ }^{47}$ L. Jacinto García, Comer como Dios manda, 1999, Barcelona, Destino (Áncora y Delfín, 868), p. 124.

${ }^{48}$ Cfr. id., p. 140. En el Antiguo Testamento, en el libro de Isaías (1, 6): a planta pedis usque ad verticem non est in eo sanitas; vulnus et livor et plaga tumens non est circumligata nec curata medicamine neque fota oleo. 
Palas Atenea quien obsequió el olivo a los mortales y enseñó a los habitantes del Ática su cultivo y la obtención de su jugo, el aceite. Cuenta la leyenda que esta deidad se enfrentó a Poseidón por el dominio del Ática; los dioses, entonces, decidieron dirimir el conflicto, otorgando la victoria a quien entregara el don más valioso a los habitantes de la región; así, mientras Poseidón hizo surgir un lago salado cerca de la Acrópolis, Atenea hizo brotar un árbol de olivo junto al Erecteion, lo cual le valió el triunfo. ${ }^{49}$ Entre los romanos, Minerva fue la diosa encargada de su custodia; de hecho, Virgilio la nombra 'inventora del olivo' ${ }^{50}$

Así, este mítico árbol de las riberas mediterráneas rápidamente se volvió insignia de la paz, señal de la tierra labrada, pues su cultivo representaba las labores pacíficas de la labranza, en contraposición a las de la caza, asociadas de forma metafórica con las actividades guerreras. El olivo implica, pues, la victoria de la paz, de la cultura, de la sabiduría, no en vano Atenea es su creadora: "con esto se nutre el generoso olivo, también grato a la paz"; 51 y, probablemente en recuerdo del triunfo de la diosa, asimismo es símbolo de la victoria. En efecto, con sus ramas se trenzaron las coronas de los vencedores, y se dice que los triunfadores de las Panateneas y de los Juegos olímpicos recibían, como recompensa, coronas trenzadas con las ramas del árbol sagrado de la Acrópolis. ${ }^{52} \mathrm{Si}$ bien la corona triunfal se hacía con hojas de laurel, Aulo Gelio explica que entre las coronas militares "existe [...] la de olivo, que suelen usar quienes no estuvieron en combate, pero organizan un triunfo", ${ }^{53}$ es decir, aquellos que sin participar directamente en la acción armada, contribuyeron de manera significativa a la obtención de la victoria.

${ }^{49}$ Cfr. Ov., Met., VI, 70-82; P. Grimal, Diccionario de mitología griega y romana, 1981, Barcelona, Paidós, p. 60.

${ }^{50}$ Virg., G., I, 18-9: oleaeque Minerva / inventrix.

${ }^{51}$ Id., II, 425: Hoc pinguem et placitam Paci nutritor oliuam. Cfr. también Isid., Orig., XVII, 7, 62: Est autem ipsa arbor pacis insignis.

${ }^{52}$ Cfr. J. A. Pérez Rioja, Diccionario de símbolos y mitos, 1971, Madrid, Tecnos, p. 41.

${ }^{53}$ Gell., V, vi, 3-4: oleaginea qua uti solent qui in proelio non fuerunt sed triumphum procurant. Trad. Amparo Gaos Schmidt, en Aulo Gelio, Noches Áticas, 2002, intr., trad., nts. e índ. on., UNAM, Bibliotheca Scriptorum Graecorum et Romanorum Mexicana. 
Del mismo modo, para los hebreos, el olivo alcanzó un lugar privilegiado en el terreno simbólico. La Biblia cita el aceite más de ciento cuarenta veces, y el árbol aparece mencionado allí en casi mil ocasiones; ${ }^{54}$ por ejemplo, en el Antiguo Testamento, se dice de la tierra prometida que es una tierra pródiga en olivares y aceite, ${ }^{55} \mathrm{y}$ de la sabiduría, que ésta ha arraigado en la heredad de Dios, 'como un hermoso olivo en los campos'. ${ }^{56}$ Igualmente significativo resulta el episodio narrado por el Génesis, cuando, después del Diluvio, Noé echa a volar una paloma, a fin de saber si las aguas ya se han disipado de la tierra, y el ave regresa entonces al arca con una rama de olivo en el pico:

Después de esperar otros siete días, volvió a enviar la paloma fuera del arca; ella regresó al atardecer, trayendo en su pico un ramo verde de olivo, así pues, supo Noé que habían disminuido las aguas sobre la tierra. ${ }^{57}$

Esta proverbial imagen, trascendiendo épocas y culturas, se ha convertido en el símbolo por antonomasia de la paz, tanto de Dios con el hombre como de los seres humanos entre sí: pensemos si no en la célebre litografía de Picasso, La paloma, la cual se ha vuelto icono universal de la paz.

Sin embargo, las implicaciones que tuvo el olivo para el antiguo pueblo judío no terminan aquí, pues tuvo un empleo importantísimo en la liturgia. ${ }^{58}$ De hecho, los hebreos se sirvieron de los óleos para la

${ }^{54}$ L. Jacinto García, op. cit., p. 147.

${ }^{55} 2$ R, 18, 32: terram olivarum et olei; también, Deut, 8, 8: terram [...] in qua ficus et mala granata et oliveta nascuntur, terram olei.

${ }^{56} \mathrm{Si}, 24,19:$ quasi oliva speciosa in campis.

${ }^{57}$ Gen, 8, 10-11: expectatis autem ultra septem diebus aliis, rursum dimisit columbam ex arca. At illa venit ad eum ad vesperam portans ramum olivae virentibus foliis in ore suo; intellexit ergo Noe quod cessassent aquae super terram.

${ }^{58}$ Según las palabras que Dios le dirige a Moisés, el óleo santo debía ser elaborado a partir de los siguientes aromas: "de mirra pura, quinientos siclos; de cinamomo, la mitad, esto es, doscientos cincuenta; igualmente de caña, doscientos cincuenta; de casia, también quinientos siclos, [...] un sextario de aceite de oliva, y harás [con ello] el óleo santo de la unción". Ex 
consagración de templos, altares y diversos objetos culturales, ${ }^{59}$ para mantener siempre encendida la llama del candelabro sagrado, meno$r a h ;{ }^{60}$ para las ofrendas sacramentales; ${ }^{61}$ para la unción de los difuntos; ${ }^{62}$ pero, sobre todo, para ungir a sus reyes ${ }^{63}$ y sumos sacerdotes. ${ }^{64}$

El cristianismo hizo suyas las prácticas hebraicas de la unción con óleo, pues este líquido consagrado es utilizado ya no sólo en los sacramentos de la unción de los enfermos y de la ordenación sacerdotal, sino además en los del bautismo y de la confirmación. Más aún, se podría decir que los cristianos, en última instancia, deben su nombre al aceite, dado que con dicha denominación se alude a los seguidores del Cristo, voz griega que significa el 'Ungido', lo mismo que en hebreo el término Mesías.

En efecto, el olivo y su aceite se vuelven ingredientes fundamentales durante la vida de Jesús en la tierra, e incluso se podría decir que, en un sentido amplio, tienen mucho que ver con su muerte. En vida, el olivo se hace presente en tres momentos de la existencia terrena de Jesús: primero, cuando en Betania es ungido por María; ${ }^{65}$ segundo, cuando poco antes de su aprehensión se retira al huerto de Getsemaní

30, 22-25: locutusque est Dominus ad Mosen dicens sume tibi aromata, primae et myrrhae e electae quingentos siclos, et cinnamomi médium, id est, ducentos quinquaginta siclos, calami similiter ducentos quinquaginta, cassiae autem quingentos siclos in pondere sanctuarii, olei de olivetis mensuram hin; faciesque unctionis oleum sanctum.

${ }^{59} \mathrm{Cfr}$. Lev, 8, 10-11: tulit et unctionis oleum, quo linivit tabernaculum cum omni supellectili sua. Cumque sanctificans aspersisset altare septem vicibus, unxit illud et omnia vasa eius, labrumque cum basi sua sanctificavit oleo.

${ }^{60} \mathrm{Cfr}$. Ex, 27, 20: praecipe filiis Israhel ut adferant tibi oleum de arboribus olivarum purissimum piloque contusum ut ardeat lucerna semper; también Lev, 24, 2-4.

${ }^{61}$ Lev, 7, 12: si pro gratiarum actione fuerit oblatio offerent panes absque fermento conspersos oleo et lagana azyma uncta oleo coctamque similam et collyridas olei admixtione conspersas. Cfr. también Gen, 35, 14: ille vero erexit titulum lapideum in loco quo locutus ei fuerat Deus libans super eum libamina et effundens oleum.

${ }^{62} \mathrm{Cfr}$. Jn, 19, 40: venit autem et Nicodemus [...] ferens mixturam murrae et aloes quasi libras centum. Acceperunt ergo corpus Iesu et ligaverunt eum linteis cum aromatibus sicut mos Iudaeis est sepelire.

${ }^{63}$ Cfr. $1 S, 10,1 ; 16,12-13 ; 1 R, 1,39 ; 2 R, 9,6 ; 11,12$.

${ }^{64}$ Cfr. Ex, 29,7; Lev, 4, 3; 5, 16; 8,12.

${ }^{65} \mathrm{Mt}, 26,6-13 ; \mathrm{Mc}, 14,3-9 ; \mathrm{Jn}, 12,1-9$. 
(palabra hebrea que quiere decir 'lagar de aceites', situado al pie del Monte de los olivos), donde, al cobijo de los olivares, encuentra consuelo a su agonía. Por último, una vez que Jesús ha muerto, su cuerpo nuevamente recibe el óleo que corresponde a los difuntos, a fin de poder darle adecuada sepultura: "tomaron, pues, el cuerpo de Jesús y lo ciñeron con vendas con aromas, tal como es la costumbre judía para sepultar". ${ }^{66}$

Más aún, el aceite es símbolo del mismo espíritu de Dios, es decir, de la gracia divina y del propio dispensador de la gracia, el Espíritu Santo; el aceite, por lo tanto, también supone connotaciones de dicha, alegría y felicidad:

el espíritu del Señor está sobre mí, porque me ha ungido el Señor [...] para consolar a todos los que lloran, [...] para darles corona en lugar de ceniza; aceite de gozo en lugar de manto de luto; alabanzas en lugar de espíritu de tristeza. ${ }^{67}$

En consecuencia, hablar del aceite es hablar de uno de los elementos de mayor valoración material y trascendencia espiritual entre los pueblos mediterráneos; de hecho, este líquido forma parte de lo que usualmente se conoce como la Tríada mediterránea de la alimentación. ${ }^{68} \mathrm{El}$ aceite, junto con el pan y el vino, conforma esta trilogía, cuyo elevado valor simbólico, desde el inicio de los tiempos, se mezcló indisolublemente con el ámbito religioso: olivo, pan y vino constituyen un factor esencial e indiscutible de la identidad mediterránea,

${ }^{66} \mathrm{Jn}, 19$, 40: acceperunt ergo corpus Iesu et ligaverunt eum linteis cum aromatibus sicut mos Iudaeis est sepelire.

${ }^{67}$ Is , 61, 1-3: spiritus Domini super me, eo quod unxerit Dominus [...], ut consolarer omnes lugentes [...], ut [...] darem eis coro-nam pro cinere, oleum gaudii pro luctu, pallium laudis pro spiritu maeroris.

${ }^{68}$ Cfr., por ejemplo, F. Pérez Jiménez, "La dieta mediterránea. Una herencia cultural saludable", en A. Pérez Jiménez y G. Cruz Andreotti (eds.), Dieta mediterránea. Comidas y hábitos alimenticios en las culturas mediterráneas, 2000, Madrid, Ediciones Clásicas (Mediterránea, 6), p. 9; M. Toussaint-Samat, Historia natural y moral de los alimentos, 1991, Madrid, Alianza, 9 v., v. 1: La miel, las legumbres y la caza, p. 11; L. Jacinto García, op. cit., p. 119-60. 
pues no sólo definen y distinguen de manera categórica, hasta hoy en día incluso, los hábitos alimenticios de los pobladores de esa región, sino constituyen la base sobre la que se erigen material, espiritual y simbólicamente las culturas de la cuenca del Mediterráneo.

Para los antiguos griegos, romanos, judíos y cristianos, ningún otro árbol llegó a ser tan provechoso, tan apreciado y tan venerado como el olivo, pues sus frutos y su aceite, trascendiendo los estrictos valores nutritivos y su aplicación en el terreno de lo cotidiano, alcanzaron -como prácticamente ningún otro producto alimenticio- la más elevada cualidad metafórica, la de símbolos sagrados. Más aún, el aceite de oliva fue el único elemento de la trilogía mediterránea unánimemente aceptado y glorificado por las religiones de la antigüedad, las cuales supieron ver en el olivo un emblema de paz, sabiduría y felicidad. En suma, el aceite fue para los pueblos del Mediterráneo, de todas las épocas, un apreciadísimo combustible, porque no sólo iluminaba las casas y deleitaba las cocinas, sino, además, elevaba el espíritu. 
La reproducción total o parcial de este artículo se podrá hacer si el ITAM otorga la autorización previamente por escrito. 